\title{
Perinatal Outcomes of Hypertensive Pregnancy: A Case Control Study
}

\author{
Acharya $\mathrm{N}^{1}$, Dhungana $\mathrm{D}^{2}$, Gupta $\mathrm{V}^{3}$
}

\section{ABSTRACT}

Background: Hypertensive disorders of pregnancy (HDP) are one of the maternal diseases that cause the most detrimental effects to the mother and the fetus. Objective: This study was conducted to compare the perinatal outcomes of neonates delivered by hypertensive mothers and normal mothers. Methods: This comparative hospital based study was conducted in Nepalgunj Medical College Teaching Hospital, Kohalpur from December 2014 to December 2015. Fifty mothers fulfilling the inclusion criteria and their fetal outcome in form of still birth and newborn babies were taken for the study and 50 healthy mothers with normotensive pregnancies and their newborn babies or fetal outcome were taken as control. They were followed up till their hospital stay in NICU or postnatal ward and final outcomes were noted. Results: The prevalence of HDP in our hospital was $2.16 \%$. Among neonates, $27(54 \%)$ in case group and $9(18 \%)$ in control group were low birth weight which is statistically significant. It was found that $18(36 \%)$ neonates in case group and $7(14 \%)$ neonates in control group were IUGR(Intrauterine growth retardation). Seventeen (34\%) neonates in case group were preterm as compared to $2(4 \%)$ neonates in control group ( $p$ value $<0.001$ ). Conclusion: Pregnancies complicated by hypertension were characterized by an increase in the rate of preterm delivery and low birth weight infants compared with normal pregnancies.

\section{Key words: Hypertensive disorders of pregnancy (HDP), Low birth weight, Prematurity, Perinatal period}

1. Dr. Niraj Acharya

2. Dr. Diwas Dhungana

3. Prof. Veena Gupta

Address for correspondence:

Dr. Niraj Acharya

Assistant Professor

Department of Paediatrics

Nepalgunj Medical College \& Teaching Hospital

Email: drnirajacharya@gmail.com

\section{INTRODUCTION}

Hypertensive disorders of pregnancy (HDP) are one of the maternal diseases that cause the most detrimental effects to the mother and the fetus ${ }^{1}$.

Hypertension during pregnancy is defined as a sustained systolic blood pressure of $140 \mathrm{mmHg}$ or more and/or a diastolic blood pressure of $90 \mathrm{mmHg}$ or more. This is best confirmed when evidence is present on 2 occasions at least 6 hours apart but within 7 days $^{2}$.

The Working Group of the NHBPEP-National High Blood Pressure Education Program (2000) has categorized hypertensive disorders of pregnancy into 4 types $^{1}$ :

1. Gestational Hypertension: Hypertension $1^{\text {st }}$ diagnosed after 20 weeks gestation not accompanied by proteinuria.

2. Pre-eclampsia/pre-eclamptic toxemia (PET) - Eclampsia: Hypertension $1^{\text {st }}$ diagnosed after 20 weeks gestation accompanied by proteinuria greater than $0.3 \mathrm{~g}$ in 24 hours urine collection or greater than $3+$ in a random sample; Eclampsia is occurrence of seizures in women with preeclampsia that cannot be attributed to other causes.

3. Chronic Hypertension: Hypertension present before pregnancy or $1^{\text {st }}$ diagnosed before 20 weeks gestation.

4. Pre-eclampsia superimposed on chronic hypertension. Gestational hypertension is the dominant cause of hypertension in pregnant population followed by preeclampsia - eclampsia while chronic hypertension is seen in small number of patients ${ }^{1,3}$.

Hypertensive disorders of pregnancy (HDP) predispose women to acute or chronic utero-placental insufficiency, resulting in ante or intra-partum asphyxia that may lead to fetal death, intrauterine growth retardation and/or preterm delivery ${ }^{4,5}$.

The complications can be prevented by more widespread use of prenatal care, education of primary medical care personal, prompt diagnosis of high risk patients and timely referral to tertiary medical centers and institutional mangement $t^{3,6,7,8}$.

Since no such study has been carried out in this part of the country, the present study was carried out with the purpose to see perinatal outcome of neonates with maternal hypertensive disorders in pregnancy.

\section{MATERIAL AND METHODS}

A hospital based comparative study was carried out to evaluate the perinatal outcome of neonates delivered by hypertensive mothers without other comorbidities and to compare with the outcome of control group.

The data was collected from the NICU and the Department of Obstetrics and Gynecology of Nepalgunj Medical College 
Teaching Hospital Kohalpur, Banke. The study was carried out from December 2014 till December 2015.

Fifty mothers which were given clinically the provisional diagnosis of hypertension in pregnancy admitted in our hospital for further management and neonates delivered to such hypertensive mothers fulfilling the inclusion criteria were taken as cases. Fifty normotensive mothers admitted as full term normal pregnancy in labor and without any complications during pregnancy were taken as control and their fetal outcome (i.e. still birth if any and neonates) were assessed for comparison.

Data regarding the demographic parameters like age, parity, literacy status, socio-economic status, antenatal checkup, gestational age, time of onset of raised blood pressure, associated medical disorders specially the history of hypertensive disorder during their previous pregnancy, family history of hypertension, mode of delivery, and fetal complications like intra uterine death (IUD) were recorded in a structured questionnaire.

Neonatal parameters like perinatal asphyxia, Apgar score, sex, gestational age, birth weight, small for gestational age, NICU admission and duration of stay in hospital, respiratory distress due to hyaline membrane disease (HMD), transient tachypnoea of newborn(TTNB), neonatal sepsis (NNS), meconium aspiration syndrome (MAS), Birth asphyxia (BA) were recorded.

The cases were followed up till their hospital stay in NICU or postnatal ward and outcome was noted. Statistical analyses of clinical and demographic factors were carried out.

\section{RESULT}

Out of total 100 mothers, 2 mothers from hypertensive group had twin delivery and 2 mothers from normotensive group were chosen with twin pregnancy. But only the first neonate from the twin delivery was selected for study from both the study groups.

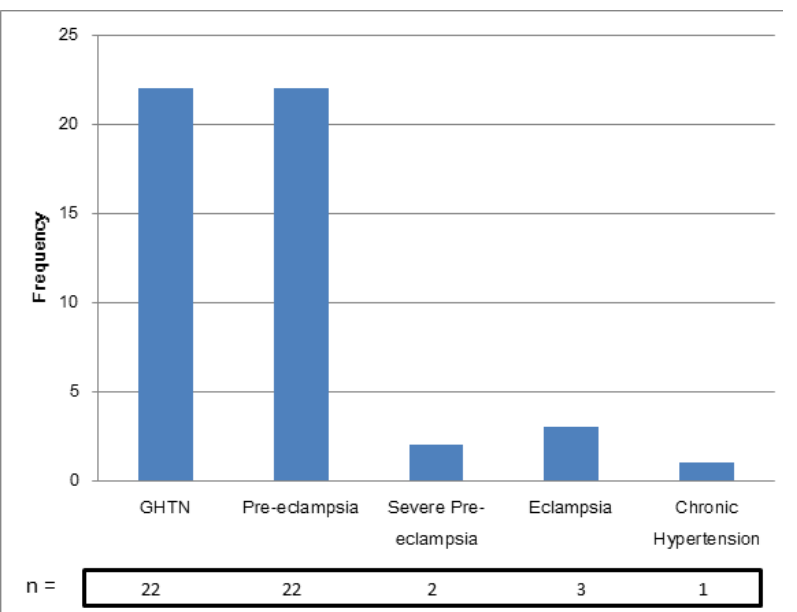

Figure 1: Distribution of cases according to type of hypertension
The above bar diagram shows that in the case group $(n=50)$ maximum cases were diagnosed as gestational HTN 22 (44\%) and pre-eclampsia $22(44 \%)$ cases, followed by eclampsia only in $3(6 \%)$, severe eclampsia $2(4 \%)$ and chronic HTN $1(2 \%)$. Thus $88 \%$ of the cases fell in GHTN and pre-eclampsia group.

Out of total 50 neonates delivered from mothers with HDP, 3 were intrauterine death/stillbirth (IUFD). Similarly 1 intrauterine death (IUFD) was recorded out of 50 deliveries from normotensive mothers.

Among neonates, $27(54 \%)$ in case group and $9(18 \%)$ in control group were low birth weight which is statistically significant.

It was found that $18(36 \%)$ neonates in case group and $7(14 \%)$ neonates in control group were IUGR (Intrauterine growth retardation). Seventeen (34\%) neonates in case group were preterm as compared to $2(4 \%)$ neonates in control group which is statistically significant.

\begin{tabular}{|c|c|c|c|c|c|c|c|c|c|c|}
\hline \multirow{2}{*}{$\begin{array}{l}\text { 음 } \\
\text { ํํ }\end{array}$} & \multirow{2}{*}{ 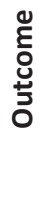 } & \multicolumn{7}{|c|}{ Perinatal complications } & \multirow{2}{*}{ 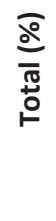 } & \multirow{2}{*}{$\frac{0}{\frac{0}{\pi}}$} \\
\hline & & $\begin{array}{l}\overline{\widetilde{J}} \\
\text { है } \\
\text { zon }\end{array}$ & 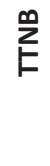 & $\varangle$ & $\sum_{\text {I }}$ & $\sum_{\Sigma}^{n}$ & $\sum_{z}^{n}$ & 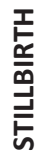 & & \\
\hline \multirow{2}{*}{ 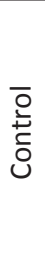 } & $\stackrel{\stackrel{\nu}{z}}{\bar{\alpha}}$ & $\mathcal{F}$ & $N$ & -1 & 0 & 0 & $m$ & ' & $\begin{array}{l}\sigma \\
\infty \\
\infty \\
o \\
o \\
\text { g }\end{array}$ & \multirow{3}{*}{$\begin{array}{l}-1 \\
\text { ¿े } \\
\text { v }\end{array}$} \\
\hline & 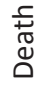 & 0 & 0 & 0 & $r$ & 0 & 0 & $r$ & 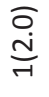 & \\
\hline \multicolumn{2}{|c|}{ 跑 す } & $\begin{array}{l}\widetilde{O} \\
\dot{\Phi} \\
\stackrel{\Phi}{Y}\end{array}$ & $\underset{\sim}{\tilde{j}}$ & $\underset{-1}{\stackrel{\partial}{\mathfrak{d}}}$ & 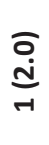 & 0 & $\begin{array}{l}\stackrel{\partial}{0} \\
\stackrel{\omega}{m}\end{array}$ & $\underset{\substack{\text { d } \\
\text { d }}}{ }$ & $\begin{array}{l}\text { 무 } \\
\text { ¿ } \\
\text { 잉 }\end{array}$ & \\
\hline \multirow{2}{*}{$\stackrel{\stackrel{\Xi}{~}}{\tilde{J}}$} & 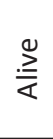 & $\stackrel{\stackrel{\sim}{\neg}}{\circ}$ & $m$ & $\sigma$ & $m$ & $\sim$ & 우 & ' & 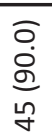 & \multirow{3}{*}{$\begin{array}{l}\tilde{O} \\
\dot{0} \\
v\end{array}$} \\
\hline & $\begin{array}{l}\frac{c}{+} \\
\text { J } \\
0\end{array}$ & 0 & 0 & $\sim$ & $m$ & 0 & 0 & $m$ & 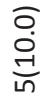 & \\
\hline \multicolumn{2}{|c|}{$\frac{\bar{\partial}}{\bar{\Phi}}$} & 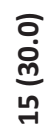 & $\frac{\partial}{\dot{b}}$ & $\begin{array}{l}\underset{0}{\mathbf{N}} \\
\underset{\mathrm{I}}{-1}\end{array}$ & $\underset{0}{\stackrel{0}{త ్}}$ & $\begin{array}{l}\bar{\partial} \\
\underset{N}{\mathbf{d}}\end{array}$ & 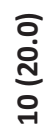 & 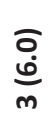 & $\begin{array}{l}\text { 무 } \\
\text { 웅 } \\
\text { 웅 }\end{array}$ & \\
\hline
\end{tabular}

Table I : Perinatal complications and neonatal outcome in study group

The table above shows different morbid conditions like TTNB, BA, HMD, MAS, NNS and still birth in both the case and control group.

In control group there was $1(2 \%)$ stillbirth compared to 3 $(6 \%)$ in case group. Similarly $22 \%$ of case had birth asphyxia followed by $20 \%$ NNS, $12 \%$ HMD, $6 \%$ TTNB, $4 \%$ MAS in case group as compared to $2 \% \mathrm{BA}, 6 \% \mathrm{NNS}, 2 \% \mathrm{HMD}, 4 \%$ TTNB and no MAS in control group. It showed increased perinatal 
morbidity in HDP as compared to normotensive pregnancy and it is statistically significant ( $p$ value $<0.01$ ).

\begin{tabular}{|c|c|c|c|c|c|c|c|}
\hline \multirow{2}{*}{$\begin{array}{c}\text { Perinatal } \\
\text { Outcome }\end{array}$} & \multicolumn{2}{|c|}{$\begin{array}{c}\text { Groups, } \\
\mathbf{n}(\%)\end{array}$} & \multirow{2}{*}{$\begin{array}{c}\text { Total } \\
(\%)\end{array}$} & \multirow{2}{*}{$\begin{array}{c}\mathbf{P} \\
\text { value }\end{array}$} & $\begin{array}{c}\text { Crude } \\
\text { OR }\end{array}$ & \multicolumn{2}{|c|}{$\mathbf{9 5 \%}$ Cl for OR } \\
\cline { 2 - 3 } \cline { 7 - 8 } & Control & Case & & & & Lower & Upper \\
\hline Alive & $\begin{array}{c}48 \\
(96.0)\end{array}$ & $\begin{array}{c}42 \\
(84.0)\end{array}$ & $\begin{array}{c}90 \\
(90.0)\end{array}$ & 0.046 & 4.571 & 0.919 & 22.730 \\
\hline Death & $\begin{array}{c}2 \\
(4.0)\end{array}$ & $\begin{array}{c}8 \\
(16.0)\end{array}$ & $\begin{array}{c}10 \\
(10.0)\end{array}$ & & & & \\
\hline Total & $\begin{array}{c}\mathbf{5 0} \\
(\mathbf{1 0 0 . 0})\end{array}$ & $\begin{array}{c}\mathbf{5 0} \\
\mathbf{( 1 0 0 . 0 )}\end{array}$ & & & & & \\
\hline
\end{tabular}

Table II: Perinatal Outcome in terms of mortality

The table II shows the perinatal outcome of neonates in term of mortality delivered in case and control groups. It shows that $8(16 \%)$ of case had mortality compared to $2(4 \%)$ in control group. Out of total 10 mortalities 4 were stillbirths of which 3 were in cases and 1 still birth was in the control group which was the first twin of twin delivery. This table signifies that perinatal mortality was 4.571 times greater than in control group and it is statistically significant ( $p$ value 0.046 ).

\section{DISCUSSION}

Hypertensive disorders of pregnancy have been identified as a major world- wide health problem, associated with increased perinatal morbidity and mortality ${ }^{\text {. }}$

Studies have shown that hypertensive disorders of pregnancy predispose women to acute or chronic uteroplacental insufficiency, there by having an effect on perinatal and neonatal outcome that may result in ante or intra partum anoxia that may lead to fetal death, intrauterine growth retardation and/or preterm delivery ${ }^{4,10}$. Of 3,826 deliveries in our hospital during the defined period of 1 year, 83 cases were managed as hypertensive disorder of pregnancy showing hospital based prevalence of HDP as $2.16 \%$.

According to several published studies, pregnancies complicated by hypertension are characterized by an increase in the rate of preterm delivery, LBW, and VLBW infants, compared with normal pregnancies.

This is true in all groups of hypertensive women independent of presence or absence of proteinuria ${ }^{11,12}$.

In the present study, $54 \%$ of the babies born to HDP study group mothers were low birth weight compared to $18 \%$ in control group. Nadkarni et al study had similar experience in their study with an incidence of $51.7 \%$ LBW babies ${ }^{9}$.

There is an increased incidence of preterm deliveries in our study. $34 \%$ of the study group mothers had preterm babies compared to $4 \%$ of their counterparts in control group. There was a statistically significant association of preterm births in HDP as compared to control group with $p$ value $<0.001$. Nadkarni et al study showed $44.3 \%$ preterm deliveries which is comparable to our study while Yadav et al study had $28.85 \%$ and Solange Regina study had $10.9 \%^{9,13,14}$.
One of the main impacts on the fetus is under-nutrition as a result of utero-placental vascular insufficiency, which leads to intrauterine growth retardation. So, fetal growth is a useful marker for fetal well-being ${ }^{15,16}$. Fetal complication associated with HDP is intrauterine growth restriction (IUGR). Pregnancies complicated by intrauterine growth restriction (IUGR), defined as a pathological process of reduced fetal growth, have been associated with an increase in perinatal mortality ${ }^{17,18}$. The incidence of small for gestational age (SGA) amongst women with HDP in our study (36\%) was higher than SGA neonates seen in control group (18\%) which is statistically significant ( $p$ value 0.043 ). Our study compares favorably to study done by Tranquilli et al., 2002, which reported incidence of $51.3 \%^{5}$.

Morbid conditions like Birth asphyxia, HMD, NNS, MAS, TTNB in newborns were considered individually, which showed specific association with HDP in mothers in our study. For Birth asphyxia it was observed in $23.4 \%$ newborn in case group compared to $2.04 \%$ in control group; HMD (12.8\%) in case group compared to $2 \%$ in control group; NNS (21.3\%) compared to $6.1 \%$ in control group and were all statistically significant ( $p$ value $<0.05$ ). Whereas morbid conditions like MAS and TTNB did not show significant correlation in mothers with HDP and normotensive mothers. Similar studies done by Nadkarni et al showed higher risk of birth asphyxia (14\%), neonatal sepsis (7.5\%) and HMD (7.3\%) in hypertensive pregnant mothers ${ }^{9}$. In one study carried out by Swetha Ananda et al showed increased association of MAS in neonates (5.4\%) born to mothers with HDP ${ }^{19}$.

In this study perinatal mortality was $8(16 \%)$ in case group, out of them, $3(6 \%)$ IUD/stillbirth, $5(10 \%)$ babies expired during the course of treatment at NICU out of 50 babies. Similarly in control group out of total 50 babies, $2(4 \%)$ had perinatal mortality out of which $1(2 \%)$ IUD/ stillbirth and $1(2 \%)$ early neonatal death. In the present study, prematurity (HMD) was the commonest cause of perinatal mortality. In the study by Shaheen et al. perinatal mortality was 41.6 percent and prematurity was the main risk factor ${ }^{20}$. In a study done by Nadkarni et al., total perinatal death was 68 (15.9\%) out of $427,40(31.1 \%)$ was early neonatal deaths and 28 (6.5\%) still births ${ }^{9}$.

\section{CONCLUSION}

HDP is a common complication in antenatal women and is a major cause of maternal and fetal morbidity and mortality. The prevalence of HDP in our hospital was $2.16 \%$.

Pregnancies complicated by hypertension were characterized by an increase in the rate of preterm delivery, LBW and VLBW infants compared with normal pregnancies. The commonest cause of perinatal mortality in the present study was prematurity (HMD) followed by birth asphyxia.

\section{REFERENCES}

1. Zamorski MA, Green LA. NHBPEP report on high blood pressure in pregnancy: a summary for family physicians. American family physician. 2001 Jul; 64(2):263-70. 
2. Prakash J, Pandey LK, Singh AK et al. Hypertension in PregnancyHospital Based Study. Journal-Association of Physicians of India. 2006 Apr 2; 54(R):273.

3. Khawaja NP, Parveen A, Hussain U. Frequency and Obstetric outcome of hypertensive disorders of pregnancy. Hypertension. 2003 Jun;1551(1):4-34.

4. Naeye RL, Friedman EA. Causes of perinatal death associated with gestational hypertension and proteinuria. American journal of obstetrics and gynecology. 1979 Jan 1; 133(1):8-10.

5. Tranquilli AL, Giannubilo SR. The" weight" of fetal growth restriction in 437 hypertensive pregnancies. Archives of gynecology and obstetrics. $2004 \operatorname{Dec} 1 ;$ 270(4):214-6.

6. Liu CM, Cheng PJ, Chang SD. Maternal complications and perinatal outcomes associated with gestational hypertension and severe preeclampsia in Taiwanese women. Journal of the Formosan Medical Association. 2008 Feb 29; 107(2):129-38.

7. Bangal VB, Giri PA, Mahajan AS. Maternal and foetal outcome in pregnancy induced hypertension: A study from rural tertiary care teaching hospital in India. International Journal of Biomedical Research. 2012 Jan 1; 2(12):595-9.

8. Yücesoy G, Özkan S, Bodur $\mathrm{H}$ et al. Maternal and perinatal outcome in pregnancies complicated with hypertensive disorder of pregnancy: a seven year experience of a tertiary care center. Archives of gynecology and obstetrics. 2005 Nov 1; 273(1):43-9.

9. Nadkarni J, Bahl J, Parekh P. Perinatal Outcome in Pregnancy Associated Hypertension. Indian pediatrics. 2001; 38:174-8.

10. Foy R, Ramsay CR, Grimshaw JM et al. The impact of guidelines on mild hypertension in pregnancy: time series analysis. BJOG: An International Journal of Obstetrics \& Gynaecology. 2004 Aug $1 ; 111(8): 765-70$.

11. Xiong $X$ and Fraser WD. Impact of pregnancy-induced hypertension on birth weight by gestational age. Paediater Perinat Epidemiol; 2004; 18(3):186-91.

12. Moutquin JM, Rainville $C$, Giroux L et al. Is a threshold increase in blood pressure predictive of preeclampsia? A prospective cohort study. Clin Exp Hypertension B; 1990; 9(2):225-35.

13. Solange Regina et al. Pregnancy induced hypertension and the neonatal outcome. Actapul. Enferm Jan/March; 2008:21.

14. Yadav S, Saxena U, Yadav R et al. Hypertensive disorders of pregnancy and maternal and fetal outcome: A case controlled study. J Indian Med Assoc 1997; 95:548-51.

15. Habli M, Levine RJ, Qian C et al. Neonatal outcomes in pregnancies with preeclampsia or gestational hypertension and in normotensive pregnancies that delivered at 35, 36, or 37 weeks of gestation. American journal of obstetrics and gynecology. 2007 Oct 31; 197(4):406-e1.

16. Saftlas AF, Olson DR, Franks AL et al. Epidemiology of preeclampsia and eclampsia in the United States, 1979-1986. American journal of obstetrics and gynecology. 1990 Aug 31; 163(2):460-5.

17. Aucott SW, Donohue PK, Northington FJ. Increased morbidity in severe early intrauterine growth restriction. Journal of perinatology. $2004 \mathrm{Jul} 1$; 24(7):435-40.

18. Richardus JH, Graafmans WC, Verloove-Vanhorick SP et al. Differences in perinatal mortality and suboptimal care between 10 European regions: results of an international audit. BJOG: An International Journal of Obstetrics \& Gynaecology. 2003 Feb 1; 110(2):97-105.

19. Shweta A, Krishna A. Perinatal outcome in growth retarded babies born to normotensive and hypotensive mothers - A prospective study. People's journal of scientific research, Jan 2012; 5(1):24-28.
20. Shaheen B, Hassan L, Obaid M. Eclampsia, a major cause of maternal and perinatal mortality: a prospective analysis at a tertiary care hospital of Peshawar. J Pak Med Assoc. 2003;53(8):346-50. 